American J. of Engineering and Applied Sciences 2 (1):165-170, 2009

ISSN 1941-7020

(C) 2009 Science Publications

\title{
Investigations of Two-Layer Earth Parameters at Low Voltage: Measurements and Calculations
}

\author{
Ramdan E. Rajab, N. Mohamad Nor and K. Ramar \\ Faculty of Engineering, Multimedia University, \\ Jalan Multimedia, 63100, Cyberjaya, Selangor, Malaysia
}

\begin{abstract}
Problem statement: The two-layer soil model at low magnitude voltage is assumed to be accurate for the measurement and calculation of the earth resistance of a combined grid-multiple rods electrode. The aim of this study is to measure and calculate the earth resistance of a combined gridmultiple rods electrode buried in a two-layer soil and to confirm the simplicity and accuracy of the used formula. Approach: Soil resistivity was measured using Wenner four point method. Advanced earth resistivity measurement interpretation techniques which include graphical curve matching based on master curves and an advanced computer program based on a genetic algorithm are used in this study. Results: Based on the resistivity data, the earth resistance value was calculated using the formulas obtained from the literature. Measurements of the earth resistance of the earthing system were also conducted using the fall of potential method. Conclusion/Recommendations: A very good agreement was obtained between the measured and calculated earth resistance values. This research is the first time ever conducted where the measured earth resistance values are compared directly with the calculated earth values.
\end{abstract}

Key words: Two layer soil model, soil resistivity, earth resistance, genetic algorithm, master curves

\section{INTRODUCTION}

The main objective of a grounding system is to provide means to dissipate electrical currents into the ground, in order to ensure the continuity of the power supply and the integrity of the equipment and to ensure that a person in the vicinity of the grounded installation is not exposed to a critical electrical shock. In order to achieve these targets, the apparent electrical resistance of the grounding system must be low enough to allow fault currents to dissipate mainly through the earthing electrode into the ground ${ }^{[1]}$.

With an increasing number, size and complexity of the substation, the earthing system design has become more challenging. A few authors ${ }^{[2-5]}$ have provided earth resistance formulas for rod beds and multiple electrodes for two-layer soils

Chow et al. ${ }^{[2]}$ listed, under one umbrella, the resistance formulas of grounding systems, namely: the buried grid, the driven rodbed and the combination of the buried grid and rodbed. The formulas were synthesized from rigorous asymptotes; which gives accuracy up to an averaged error of 5\% the research did not require empirical tables or graphs. The validity of these formulas was verified not by their derivations, since they are too lengthy, but by checking numerically, against the results of detailed-numerical methods and analytically, against asymptotes. The formulas are suitable for calculation with a handheld calculator and therefore they are useful tools for an engineer in the field.

Nahman and Djordjevic ${ }^{[3]}$ analyzed the resistance to ground of a wide set of square and rectangular grid electrodes combined with multiple rods, buried in uniform and two-layer soils using available exact computer software. Based upon the results of this analysis, analytical expressions and graphs for electrodes resistance to ground are provided, which is appropriate for practical application.

In another research done by ${ }^{[4]}$ the resistance to earth of square and rectangular grid and combined gridmultiple rods earth electrodes buried in uniform and two-layer soils were analyzed for a wide set of electrodes and soil parameters. Novel approximate expressions for earth resistance were deduced based upon the data obtained by exact computer modeling. These expressions and a set of diagrams provided can be used in the preliminary design stage of substations earthing systems for assessing the effects of various earthing system and soil parameters.

Corresponding Author: Ramdan E. Rajab, Faculty of Engineering, Multimedia University, Jalan Multimedia, 63100, Cyberjaya, Selangor, Malaysia Tel: +603-8312 5434 Fax: +603-8318 3029 
Cheng-Nan and Chien Hsing ${ }^{[5]}$ computed ground resistances and assessed ground grid safety at three 161/23.9-kV indoor-type substations in the system of the Taiwan Power Company. For computing the ground resistance, a method based on two kinds of two-layer models (i.e., grid buried in the lower-layer of two-layer soil, two-layer soil simplified with one-layer structure of the Sverak's and empirical equations) is used and compared with the method proposed by the one-layer model of the Schwarz's equation in IEEE Standard 80, 2000 edition in their findings, the ground resistance obtained by the two-layer soil simplified with one-layer structure of the empirical equation is found to be close to the measured. For assessing the safety ground grid, of the ground potential rise was computed based on the calculated ground resistance and is compared with the minimum touch voltage. It was found that the design of the ground grid at all three 161/23.9-kV indoor-type substations is unsafe under a one-layer model of the Schwarz's equation for humans with $50 \mathrm{~kg}$ body weight.

The present research is to investigate the two layer earth parameters at low magnitude voltage based on field measurements and analytical method. This study shows that it is adequate to consider a two-layer soil for the design of earthing system. This is because; it has been proven in $^{[3]}$ that a more accurate representation of the actual soil conditions can be obtained by using the two-layer soil model. This present research confirms the accuracy of the formulas from references ${ }^{[2,3]}$ for the calculation of the earth resistance of the combined gridmultiple rods electrode in two-layer soil. The field measurements were also conducted and presented in this research. Close earth resistance results were observed between the calculations and measurements.

\section{MATERIALS AND METHODS}

Field data: There are two parameters that determine the performance of earthing systems; soil resistivity and the configurations/dimensions of earth electrode. For the field measurements, the resistivity data is collected using the Wenner four-point method ${ }^{[8-10]}$. In this method, small electrodes are buried in four small holes in the earth, all at depth $\mathrm{b}$ meter and spaced (in a straight line) at intervals a meter. A test current I Ampere is passed between the two outer electrodes, the potential drop $\mathrm{V}$ is measured between the two inner electrodes using potentiometer or high-impedance voltmeter shown in Fig. 1; where $\mathrm{R}$ is obtained from V/I. Based on this resistance value, the average resistivity of the soil of different spacing can be calculated using Eq. 1: $\rho_{\mathrm{a}}=2 \cdot \pi \cdot \mathrm{a} \cdot \mathrm{R}$

Where:

$\rho_{\mathrm{a}}=$ The apparent soil resistivity

$\mathrm{a}=$ The probe spacing

A set of readings taken for various probe spacing gives a set of resistivities. In this study, the soil resistivity measurements are conducted at least twice to double check the measurements. Table 1 shows the measured apparent soil resistivity values obtained for the site. The soil resistivity values obtained from these measurements are then interpreted into two-layer soil using the master curves $^{[6]}$ and Genetic Algorithm $(\mathrm{GA})^{[7]}$.

Earth resistance of the combined grid-multiple rods electrode (calculation): In order to evaluate the accuracy between the designed and measured earth resistance values, two simple earth resistance formulas as proposed by Chow ${ }^{[2]}$ and Nahman ${ }^{[3]}$ are used.

Chow et al. ${ }^{[2]}$ presented a formula for a sunken grid and rodbed in combination for a two-layered earth. The earth resistance formulas for grid and rodbed in combination where the rods penetrate the lower layer are given by:

$$
\mathrm{R}_{\mathrm{T}}=\frac{1}{\sqrt[3]{\left(\frac{1}{\mathrm{R}_{\mathrm{g}}}\right)^{3}+\left(\frac{1}{\mathrm{R}_{\mathrm{t}}}\right)^{3}}}
$$

The resistance, $R_{\mathrm{g}}$ is:

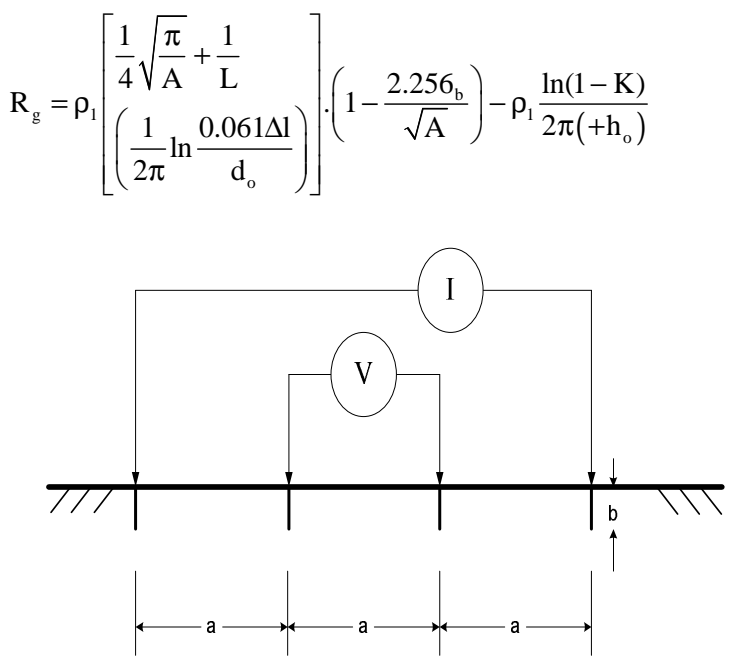


Table 1: Apparent soil resistivity

\begin{tabular}{lllllllllll}
\hline Probe spacing $(\mathrm{m})$ & 1 & 1.3 & 1.6 & 2 & 3 & 4 & 5 & 6 & 8 & 10
\end{tabular} $\begin{array}{llllllllllll}\text { Apparent } & 282 & 261 & 236 & 192 & 141 & 128 & 120 & 118 & 112 & 111\end{array}$ resistivity $(\Omega \cdot m)$

Where:

$K=\frac{\rho_{2}-\rho_{1}}{\rho_{2}+\rho_{1}}$

$\mathrm{h} \angle 0.2 \sqrt{\mathrm{A}}, \mathrm{h}_{\mathrm{o}} \angle \mathrm{h}$

$\mathrm{h}_{\mathrm{o}}=\mathrm{c}_{\mathrm{f}} \sqrt{\frac{\mathrm{A}}{2 \pi}}[\ln (1-\mathrm{k})] \frac{\mathrm{k}-1}{2 \mathrm{k}}$

$\Delta \mathrm{l}=\sqrt{\Delta \mathrm{l}_{\mathrm{x}} \Delta \mathrm{l}_{\mathrm{y}}}$

$\mathrm{R}_{\mathrm{t}}=\frac{1}{\frac{1}{\mathrm{R}_{\mathrm{a}}}+\frac{1}{\mathrm{R}_{\mathrm{b}}}}$

$\mathrm{R}_{\mathrm{a}}=\frac{\rho_{2}}{\left(1+\mathrm{h}_{\mathrm{o}}-\mathrm{h}\right)} \mathrm{g}_{\mathrm{o}} \frac{\mathrm{F}_{\mathrm{o}}}{\mathrm{N}_{\mathrm{o}}}$

$\mathrm{R}_{\mathrm{b}}=\frac{\rho_{1}}{\left(\mathrm{~h}-\mathrm{h}_{\mathrm{o}}\right)} \mathrm{g}_{\mathrm{o}} \frac{\mathrm{F}_{\mathrm{o}}}{\mathrm{N}_{\mathrm{o}}}+\frac{\rho_{1}}{\mathrm{~h}} \phi_{\mathrm{o}}$

where, it is given in Chow et al. ${ }^{[2]}$ that for the rodbed in two-layers earth:

$$
\begin{aligned}
& \mathrm{g}_{0}=\frac{1}{2 \pi}\left[\ln \left(\frac{2 \mathrm{~L}_{\mathrm{R}}}{\mathrm{d} / 2}\right)-1+\frac{\ln 2}{1+\frac{(4 \ln 2) \mathrm{h}}{\mathrm{L}_{\mathrm{R}}}}\right] \\
& \mathrm{F}=1+\left(\mathrm{N}_{0}-\frac{1}{\sqrt{\mathrm{N}_{0}}}\right) \frac{\mathrm{R}_{\mathrm{s}}}{\mathrm{R}_{1}}
\end{aligned}
$$

$\mathrm{N}_{0}=$ The number of rods:

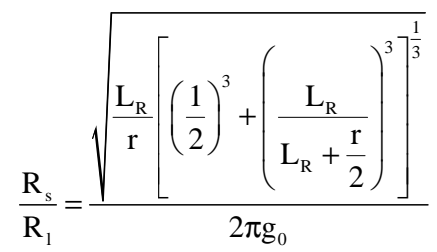

If $\mathrm{h} \angle \mathrm{l}+\mathrm{h}_{\mathrm{o}}$ :

$$
\phi=\frac{\frac{1}{2 \pi}\left(\ln \frac{1}{1-\mathrm{K}}\right)}{\sqrt{\left(\frac{\mathrm{N}_{\mathrm{o}}}{\mathrm{F}}-1\right)^{2}\left(\frac{1+\mathrm{h}_{\mathrm{o}}}{\mathrm{h}}\right)^{2}+1}}
$$

Table 2: Comparison of interpretation results two layer parameters

\begin{tabular}{llc}
\hline & $\begin{array}{l}\text { Graphical method } \\
\text { (curve matching) }\end{array}$ & $\begin{array}{l}\text { Computer program } \\
\text { (genetic algorithm) }\end{array}$ \\
\hline Top layer resistivity $(\Omega . \mathrm{m})$ & 340.00 & 331.33 \\
Bottom layer resistivity $(\Omega . \mathrm{m})$ & 102.13 & 108.46 \\
Top layer thickness $(\mathrm{m})$ & 1.10 & 1.08 \\
\hline
\end{tabular}

$$
\phi=\frac{\frac{1}{2 \pi}\left(\ln \frac{1}{1-\mathrm{K}}\right)}{\sqrt{\left(\frac{\mathrm{N}_{\mathrm{o}}}{\mathrm{F}}-1\right)^{2}+1}}
$$

and the multiple reflections of the two-layer earth effectively changes the $\mathrm{F}$ factor of $\mathrm{N}_{\mathrm{o}}$ rods (Eq. 10) changes to $F_{o}$ in the two layers earth $F_{o}=\left.F\right|_{1 \rightarrow \frac{1}{1-0.9 \mathrm{~K}}}$, where the arrow means the replacement of $\mathrm{L}_{\mathrm{R}}$ by $\frac{\mathrm{L}_{\mathrm{R}}}{1-0.9 \mathrm{~K}}$ where $\mathrm{K}$ can be calculated using Eq. 4 .

Nahman et al. ${ }^{[3]}$ presented a formula for a sunken grid and rodbed in combination in a two-layered earth as:

$\mathrm{R}_{\mathrm{T}}=\mathrm{R}_{\mathrm{u}} \mathrm{C}_{\mathrm{r}}$

Where:

$$
\mathrm{R}_{\mathrm{u}}=0.13 \frac{\rho_{1}}{\sqrt{\mathrm{A}}}\left(1-\frac{2}{3} \frac{\mathrm{L}_{\mathrm{R}}}{\sqrt{\mathrm{A}}}\right) \cdot \ln \left(\frac{2400 \sqrt{\mathrm{A}}}{\mathrm{N}_{\mathrm{m}}}\right)
$$

$\mathrm{C}_{\mathrm{r}}=\left(\frac{\rho_{2}}{\rho_{1}}\right)^{\mathrm{x}}$

$X=0.59 \ln \left(\frac{15.5}{h}\right)+0.016 \ln (4.2 \mathrm{~h})\left(\ln \left(\mathrm{N}_{\mathrm{m}} \sqrt{\mathrm{A}}\right)\right)^{2} \Rightarrow$ for $\frac{\rho_{2}}{\rho_{1}}<1$

$X=0.57 \ln \left(\frac{8.5}{h}\right)+0.016 \ln (10 h) \ln \left(N_{m} A\right) \Rightarrow$ for $\frac{\rho_{2}}{\rho_{1}}>1$

The calculated earth resistance values using the formulas from ${ }^{[2,3]}$ and together with its measured values are shown in Table 3 .

The examined earthing system is a 4-mesh combined grid-multiple rods electrode in two-layer earth, as shown in Fig. 4. Soil resistivity values of both layers and thickness of the top layer are shown in Table 2. The area of the grid is $10 \times 10 \mathrm{~m}^{2}$. The burial depth of the grid is $0.5 \mathrm{~m}$. The multiple rods depth is $3 \mathrm{~m}$. 
Table 3: Comparison of resistance values of the combined gridmultiple rods electrode

\begin{tabular}{llll}
\hline & Calculated resistance $(\Omega)$ & $\begin{array}{l}\text { Measured } \\
\text { resistance }(\Omega)\end{array}$ \\
& $\begin{array}{l}\text { Graphical } \\
\text { Method (curve } \\
\text { matching) }\end{array}$ & $\begin{array}{l}\text { Computer } \\
\text { program }(\text { genetic } \\
\text { algorithm) }\end{array}$ & $\begin{array}{l}\text { Fall of } \\
\text { potential } \\
\text { method }\end{array}$ \\
Reference & 6.09 & 6.30 & 6.23 \\
\hline Chow et al. $^{[1]}$ & 6.09 & 6.14 & \\
Nahman and & 6.00 & & \\
Jordjevic $^{[2]}$ & &
\end{tabular}

\section{RESULTS}

There are two parameters that determine the performance of earthing systems; soil resistivity and the configurations/dimensions of earth electrode. For the field measurements, the resistivity data is collected using the Wenner four-point method. The earth resistance was measured using the fall-of-potential method and found to be $6.23 \Omega$. Two methods were used: first, calculated method based on the formulas proposed by Chow ${ }^{[2]}$ and Nahman ${ }^{[3]}$ for the combined grid-multiple rods electrode; secondly, measured earth resistance using the fall-of-potential method. Generally, as shown in Table 3, close results were obtained between the two methods.

\section{DISCUSSION}

Earth resistance soil resistivity interpretation of two layer soil model: Many researchers ${ }^{[8,11,12]}$ have used the two-layer earth model as a good compromise between the simple uniform earth model and the multilayer model. In this research, the representation of nonhomogeneous soil for earthing system design for the two layer soil model is presented. Here the apparent soil resistivity data was obtained from soil resistivity measurements at the proposed site of the earthing system as shown in Table 1 . The soil resistivity data is interpreted into two layers of soil, using the master resistivity curves ${ }^{[6]}$ and Genetic Algorithm $(\mathrm{GA})^{[7]}$. For the purpose of a better understanding on the soil interpretation methods, some details are included in the respective research.

Master resistivity curves: The resistivity values of the proposed site are plotted against the electrode spacing. The result is analysed using the Master Curves, where the upper layer resistivity, $\rho_{1}$, lower layer resistivity $\rho_{2}$ and thickness of the first layer, $h$ obtained at the proposed site using the master curves are obtained. Figure 2 shows a graph of the apparent resistivity $\rho_{a}$ of the proposed site, plotted against the spacing a on a logarithmic scale with the same modulus as the master curves. Figure 2 is then compared with a set of theoretical master curves (Fig. 3), computed and produced by Orellana and Mooney ${ }^{[6]}$. The individual curves are described in terms of a reflection coefficient $\mathrm{K}$ using Eq. 4.

The interpretation of a two layer apparent resistivity graph can be done by superposing Fig. 2 and then shifting it over the master curves of Fig. 3, keeping the coordinate axes parallel, until a reasonable match is obtained with one of the master curves or with an interpolated curve.

There are also resistivity data available in the booklet ${ }^{[6]}$, which make up for the master curves. From the analysis, the values of the three parameters (upper layer resistivity, $\rho_{1}$, lower layer resistivity $\rho_{2}$ and thickness of the first layer, $h$ are obtained for the proposed field site.

Genetic Algorithm (GA): The method and formulas adopted in this present study is taken from the remarkable study by Gonos and Stathopulos ${ }^{[7]}$.

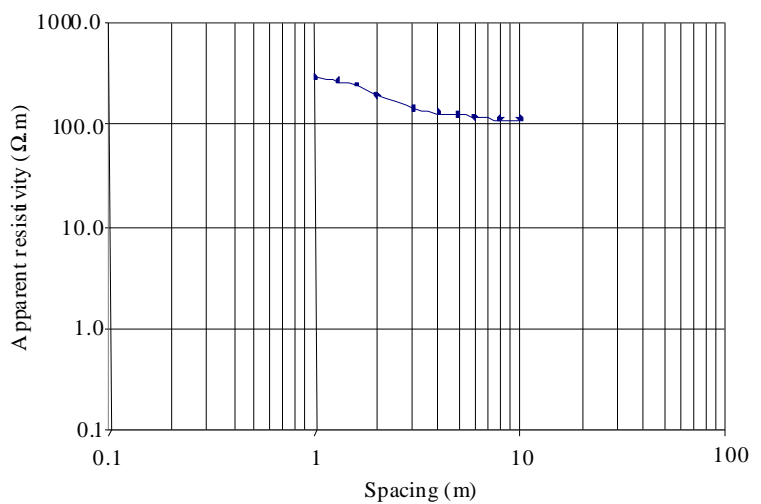

Fig. 2: Measured soil resistivity curve

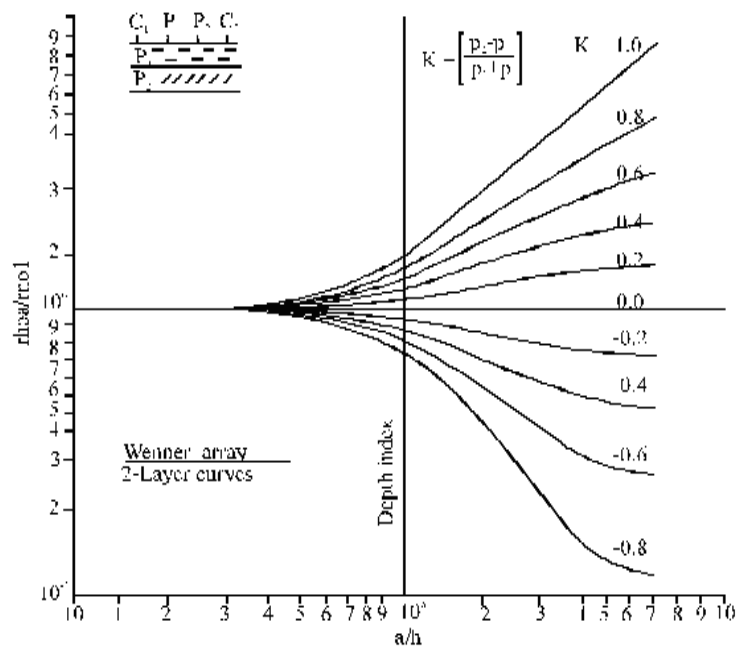

Fig. 3: Theoretical master curves for the wenner array (reproduced from ${ }^{[6]}$ ) 
In this method, the calculation of the parameters of a two-layer structure of the earth is an optimization problem. For the computation of the three parameters (soil resistivity of both layers and thickness of the upper layer), the minimization of the function $F_{\mathrm{g}}$ is necessary:

$$
\mathrm{F}_{\mathrm{g}}=\sum_{\mathrm{i}=1}^{\mathrm{N}} \frac{\left|\rho_{\alpha \mathrm{i}}^{\mathrm{m}}-\rho_{\alpha \mathrm{i}}^{\mathrm{c}}\right|}{\rho_{\alpha \mathrm{i}}^{\mathrm{m}}}
$$

Where:

$\rho_{\alpha \mathrm{i}}^{\mathrm{m}}=$ The $\mathrm{i}^{\text {th }}$ measurement of the soil resistivity when the distance between two sequential probes is $\alpha \mathrm{i}$

$\rho_{\alpha i}^{c}=$ The computed value of the soil resistivity for the same distance

The soil resistivity is calculated using equations:

$\rho_{\alpha}^{\mathrm{c}}=\rho_{\mathrm{i}}\left(1+4 \sum_{\mathrm{n}} \mathrm{K}^{\mathrm{n}}\left(\frac{1}{\sqrt{\mathrm{A}}}-\frac{1}{\sqrt{\mathrm{B}}}\right)\right)$

where, $\mathrm{n}=1 \ldots \infty, \mathrm{K}$ is the reflection coefficient, as in Eq. 1 and:

$$
\mathrm{A}=1+\left(\frac{2 \mathrm{nh}}{\mathrm{a}}\right)^{2}
$$

where, $\mathrm{B}=\mathrm{A}+3$.

A comparison of the soil resistivity values for two layer earth model interpreted using the curve matching technique $^{[6]}$ and computer based genetic algorithm ${ }^{[7]}$ is shown in Table 2. As can be shown in Table 2, close results were obtained between these two methods. This shows that either method can be used to interpret the apparent soil resistivity data as a two layer model.

Based on the resistivity values obtained from the master curves and GA, the earth resistance values are calculated for the combined grid-multiple rods earthing system using the references Chow ${ }^{[2]}$ and Nahman ${ }^{[3]}$.

Earth resistance measurement: In this study, the fallof-potential was implemented because it has several variations and is applicable to all types of ground resistance measurements ${ }^{[10]}$. The method involves passing a current into the electrode to be measured and noting the influence of this current in terms of voltage between the ground under test and a test potential electrode. Following the installation of the proposed combined grid-multiple rods electrode in two-layer soil as shown in Fig. 4, the earth resistance was measured and found to be $6.23 \Omega$. This result shows that the measured value of the earth resistance of the combined grid-multiple rods electrode is close to that calculated value.

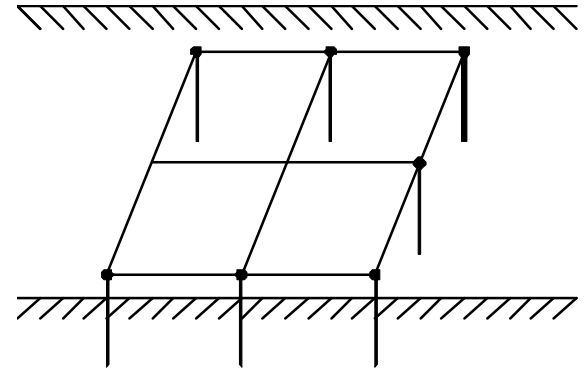

Fig. 4: Combined grid-multiple rods electrode

\section{CONCLUSION}

In this research, soil resistivity is measured and interpreted as a two layer soil model. The measurement was carried out using Wenner four point method. Advanced earth resistivity measurement interpretation techniques which include graphical curve matching based on master curves and an advanced computer program based on a genetic algorithm were employed to interpret the measurement data. Based on these soil resistivity values, the earthing system of combined gridmultiple rods electrode was constructed and the earth resistance was calculated using the formulas obtained from the literature. Measurements of the earth resistance of the earthing system were also conducted using the Fall of Potential method. A close result is obtained between the measured and calculated earth resistance value. This shows that a two-layer soil model analysis can be adequate to design for the earthing systems.

\section{ACKNOWLEDGEMENT}

The researchers wish to acknowledge the financial support of the Intensification of Research in Priority Areas and Multimedia University to wards this research project.

\section{REFERENCES}

1. Colominas, I., F. Navarrina and M. Casteleiro, 2002. A numerical formulation for grounding analysis in stratified soils. IEEE Trans. Power Delivery, 17: 587-595. DOI: 10.1109/61.997943

2. Chow, Y.L., M.M. Elsherbiny and M.M.A. Salama, 1996. Resistance formulas of grounding systems in two-layer earth. IEEE Trans. Power Delivery, 11: 1330-1336. DOI: 10.1109/61.517487

3. Nahman, J. and V.B. Djordjevic, 1996. Resistance to ground of combined grid-multiple rods electrodes. IEEE Trans. Power Delivery, 11: 1337-1342. DOI: 10.1109/61.517488 
4. Nahman, J. and V.B. Djordjevic, 1997. Resistance to earth of substation earth electrodes in uniform and two-layer soils. Elect. Eng., 80: 337-342. DOI: 10.1007/BF01370970

5. Chang, C.N. and C.H. Lee, 2006. Computation of ground resistances and assessment of ground grid safety at161/23.9-kV indoor-type substation. IEEE Trans. Power Delivery, 21: 1250-1260. DOI: 10.1109/TPWRD.2005.860245

6. Orellana, E. and H.M. Mooney, 1966. Master Tables and curves for Vertical Electrical Sounding (VES) Over Layered Structures. Madrid Interciecia.

7. Gonos, I.F. and I.A. Stathopulos, 2005. Estimation of multilayer soil parameters using genetic algorithms. IEEE Trans. Power Delivery, 20: 100-106. DOI: 10.1109/TPWRD.2004.836833

8. ANSI/IEEE Std., 2000. IEEE guide for safety in AC substation grounding, 80-2000: i-192. DOI: 10.1109/IEEESTD.2000.91902
9. ANSI/IEEE Std., 1983. IEEE guide for measuring earth resistivity. Ground Impedance and Earth Surface Potentials of a Ground System. 81-1983. E-ISBN: 0-7381-0660-7. http://ieeexplore.ieee.org/xpls/abs_all.jsp?tp=\&isnu mber $=1288 \&$ arnumber $=30647 \&$ punumber $=2464$

10. ANSI/IEEE Std., 2007. IEEE recommended practice for grounding industrial and commercial power systems. 142: 1-215. DOI: 10.1109/IEEESTD.2007.4396963

11. Dawalibi, F. and d. Mukhedkar, 1979. Influence of grounding rods on grounding grids. IEEE Trans. Power Apparat. Syst., 98: 2089-2097. DOI: 10.1109/TPAS.1979.319403

12. Sato, S. and W.S. Zaengl, 1988. Effective grounding mesh calculation technique. IEEE Trans. Power Delivery, 3: 173-182. DOI: $10.1109 / 61.4243$ 